\title{
A view of the occupational structure in Imperial and Republican China $(1640-1952)^{1}$
}

Yongqin Guo \& Zipeng Zhang \& Bas van Leeuwen \& Yi Xu,

\footnotetext{
${ }^{1}$ The research leading to these results received funding from the European Research Council under the European Union's Horizon 2020 Programme / ERC-StG 637695 - HinDI, as part of the project "The historical dynamics of industrialization in Northwestern Europe and China ca. 1800-2010: a regional interpretation".
} 


\title{
A view of the occupational structure in Imperial and Republican China (1640-1952)
}

\author{
Despite being considered a prime indicator of economic change, \\ occupational structure does not figure prominently in the debate \\ regarding the economic development of early modern China. One reason \\ is the virtual absence of occupational data before the start of the twentieth \\ century. In this paper, we make a first attempt to sketch the occupational \\ structure between ca. 1640 and 1952 using a variety of unique and rather \\ fragmented occupational sources. We find that the share of persons \\ working in agriculture remained stable until the mid-nineteenth century, \\ with the share in industry showing some growth thereafter.
}

JEL classification codes: N15, N35, J62

Key words: occupational structure, China, Qing dynasty, Republican period, household survey 


\section{INTRODUCTION}

In early modern economies, changes in the economic structure are often reflected in the occupational structure of a country (e.g., Broadberry et al., 2013). Given the heated debate on the 'Great Divergence' (Pomeranz, 2000), that is, whether parts of China were economically ahead of Northwestern Europe prior to the nineteenth century, it is at first sight surprising how little attention has been paid to occupational structure. Closer inspection reveals two main problems when analysing occupations. First, although modern (although incomplete) surveys exist for the late Qing and Republican periods (i.e., 1890-1948), the same type of information is scarce to non-existent for earlier periods. The earlier data, if they exist at all, cover only selected regions, and were collected for purposes other than occupational registration. The scarcity of sources makes it impossible to provide a comprehensive picture of Chinese occupational structure over the long term. Indeed, as pointed out by Rozaman (1981), '[m]ajor changes in stratification are difficult to document for the period 1550 to 1850 '. This is especially true for factors such as by-employment, which we largely ignore in this paper, although we do not mean to imply that they were unimportant. ${ }^{2}$

This is related to a second problem, namely occupational classification. As we discuss in Section 3, the classification of occupations in China showed great variation over time, and the change in classification system between the late Qing (ca. 1890) and the Republican period (ca. 1911) in particular represents a watershed. Hence, to standardize the historical classifications, we need to reclassify them in a standard format. These classification schemes include the International Standard Classification of Occupations (ISCO) developed by the ILO and its historical variant, the Historical International Standard Classification of Occupations (HISCO); however, neither scheme was initially developed to group the occupations by economic sector. Therefore, in this paper we rely on the Primary, Secondary, Tertiary system of occupational coding (PST) developed by Wrigley, which groups the various occupations by economic sector. ${ }^{3}$ Even though in Southeast Asian countries, this schedule is known to be biased within major

\footnotetext{
${ }^{2}$ On the contrary; in the 1920 s, 'the shoe manufacturing guild in Fuzhou was once panicked by the women who processed shoe-upper at home for others, this is not rare in other areas' (Wang, 1998), clearly suggesting that both female labour and by-employment performed a substantial role.

${ }^{3}$ http://www.geog.cam.ac.uk/research/projects/occupations/britain19c/pst.html 
sectors, most notably services, it provides the correct result at the agriculture-industryservice level (Saito et al., 2006).

Given these problems with the data and methodological limitations, this paper should just be considered as an attempt to attract research attention to this topic. Or, as the Chinese idiom goes, it is intended to 'cast a brick to attract jade'. With this in mind, the structure of the paper is as follows. In the next section, we deal with the period from ca. 1850 onwards, drawing on existing studies as well as the predecessors of the modern surveys. Section 3 looks at the pre-1850 period using four counties for which we were able to obtain scattered surveys with occupational information for at least two benchmarks, the early Qing dynasty and the Republican period: Xincheng county in Jiangxi province; Ba county in Sichuan province; Qufu county in Shandong province; and the more advanced region of Hua-Lou County, which is currently located in a Shanghai suburb. We do not claim that these are the only historical occupational data available, but it is more difficult to arrive at long-term occupational trends using other sources because they do not provide data from multiple points in time. These four case studies are then supplemented in Section 4 with occupational information from criminal records, as another source. After developing a long-term picture of occupational development in Section 5, in Section 6 we conclude that the occupational distribution remained stable up to the mid-nineteenth century.

\section{OCCUPATIONAL STRUCTURE ca. 1850-1952}

China's statistical data are relatively easily available from 1949 onward (Maddison, 1998), and the often-used estimates of Liu and Yeh (1965) can be used for 1933. These estimates, which were partly based on $\mathrm{Ou}$ (1947), were the first attempt to construct an economy-wide labour account with broad occupational classifications, and were incorporated into Liu and Yeh's endeavour to construct the Chinese national income accounts. Their estimates of both the labour and income accounts are considered most carefully done and are well accepted in studies on the modern Chinese economy (see, e.g., Perkins, 1969; Feuerwerker, 1983; Maddison, 1998) (Table 1). 
For the period 1850-1911, the situation is more complicated. The first modern survey of the population and occupations across China was conducted by the Qing government from 1890 onward, although it remained unfinished at the overturn of that government in 1911. Parts of these occupational censuses survived in many local and provincial gazetteers of numerous counties; additionally, various surveys were performed in Republican China. Hence, to arrive at an estimate of the labour force structure in 1911, we obtained a sample of the occupational structure using the data from 484 counties across China. ${ }^{4}$ Data from each county were subdivided into major economic sectors and included the labour participation rate. Table 2 lists the data from 484 available counties. The national average is based by averaging the provincial totals of those provinces having more than 1 county with data (that is we use 481 counties, i.e. 484 counties minus those provinces with data for only one county).

\section{$>>$ Insert Table $2 .<<$ \\ $>>$ Insert Figure $1 .<<$}

Based on these data, also plotted in Figure 1, we can see that the share of workers engaged in agriculture was particularly high in the peripheral provinces of Fengtian, Shandong, Shaanxi, Jilin, and Xinjiang, whereas the more central provinces had the highest shares of industry and services.

Unfortunately, few occupational censuses were conducted in the Qing dynasty before the 1890s, other than those regarding government employment and the quota of craftsmen in official manufacturing. The remarkable exception is the attempt by Guo (1991) to provide tentative estimates for the period around 1850 based on various scattered records, including criminal records. Yet, as argued by Moll-Murata (2011), Guo's estimates fall short in two ways, he overestimated the number of government employees and did not include priests. In this study, we follow Moll-Murata's estimates

\footnotetext{
4 Another source is the survey from the start of the twentieth century in Tianjin used by Rozman (1981), who used the records of the Jin men bao jia tu shuo (Records of Tianjin security defence community) to identify 1,880,000 occupational designations, comprising literati (3\%), peasants (90\%), artisans $(2.5 \%)$, and merchants (4\%). In addition, for Ziyang county in Shandong province, a survey was conducted around 1872-1882. This report was discovered in Japan in 1941, and was elaborately researched by a Japanese scholar (see Yamane Yukio, 1989, pp. 177-271). Unfortunately, it only includes the urban part of the county, so excluded it from this paper.
} 
of the employment structure for the mid-nineteenth century with four additional modifications.

1. Because agriculture in both Guo's and Moll-Murata's research refers to crops, to obtain employment in the agricultural sector we combine employment in the arable sector with that of cattle breeders, fishers, and hunters as estimated by Guo. However, his estimate for the agricultural sector essentially assumes that everyone who is recorded as a farmer in the official data was indeed a farmer, yet 'farmer' is a social classification referring to people living in the countryside, as well as an actual occupation. Therefore, based on the rural commercialization shares ( $\mathrm{Xu}$ et al. forthcoming), we eliminate a share of $\sim 7$ per cent from agriculture, divided equally between the industry and service sectors.

2. Salt makers, artisans, miners, and shipbuilders are included in the industrial sector.

3. Merchants, other servants, landowners, nobility, civilian officials, military, runners, and priests as estimated by Guo, and adjusted by Moll-Murata, are included in the service sector.

4. Guo assumed that the male labour participation rate was 50.5 per cent, and the female rate was 37.5 per cent. With a gender ratio of 100 women to 116 men, this results in a total participation rate of $\sim 42.5$ per cent.

Table 1 lists the structure of the labour force between 1850 and 1933 according to the estimates described above, and shows a high proportion of people working in agriculture and an increase in the proportion of people working in services after 1850. However, the question remains whether there was a similar occupational distribution in the early-mid Qing. Unfortunately, it is difficult to find information on earlier periods except from some scattered and fragmentary sources. In the following section, we deal with some rare samples of surviving occupational information in census-like sources from early modern China. To facilitate the time-series comparison, we focus on regions that have data for both the early-mid Qing and the early twentieth century. In Section 4, we discuss additional sources of occupational data, as well as provide tentative estimates of the occupational structure based on data from criminal records. 


\section{HOUSEHOLD CENSUSES: THE OCCUPATIONAL STRUCTURE IN COUNTY SAMPLES}

\section{Introduction}

As discussed above, the only estimate for the period before modern surveys is from Guo (1991), who used a wide array of scattered evidence to arrive at some sort of national estimate for ca. 1850. According to his method, the only sources of insight into the occupational puzzle of early modern China are the rare cases of household surveys or samples of occupational data derived from criminal records. Whereas the former have the advantage of including all social classes, they are only available for a few counties and thus only cover a very small part of China. The latter source is national in principle, but is biased towards certain social classes. In this section, we deal with local household surveys insofar as they provide multiple benchmarks over time, which makes it easier to trace temporal developments. Criminal records are discussed in Section 4.

The main fallacy in comparing pre-1850 data with the later period is differences in classification. In general, from the late Qing period (ca. 1880) until New China (1948), the government conducted occupational surveys into officially designated categories such as 'literati, peasants, workers, and merchants'. ${ }^{5}$ The latter three classifications refer to the population serving in the agricultural, industrial, and service sectors. In some cases, however, different classifications of the occupational structure are used, for example the 1938 survey of Jiangxi province categorizes barbers, cooks, servants, and boatmen as 'workers'. Hence, for this survey, one cannot use the term 'workers' to mean industrial workers alone, and the original data must be modified to match the PST scheme.

The interpretation of occupational surveys before the late Qing is even less clear. At that time, households were divided into miscellaneous occupational classes instead of into these 'four types', and they are less easy to map onto the occupational classifications with which we are familiar today. In practice, most classifications such as civilian, military are available, and in some fortunate cases also others such as government employee and monk are available. ${ }^{6}$

\footnotetext{
${ }^{5}$ Literally: ‘士 (Shi), 农 (Nong), 工 (Gong), 商 (Shang)’.

${ }^{6}$ One may also question the reliability of this classification. Established firmly in the early Ming dynasty (fourteenth-fifteenth century), their practical meaning as occupational descriptors declined over time; i.e., 
Nevertheless, we did find a few scattered pieces of information that enable us to follow the occupational structure of a handful of counties over time. These counties include Xincheng county in Jiangxi province, Ba county in Sichuan province, Qufu county in Shandong province, and Hua-Lou county in present day Shanghai (Figure 2).

\section{$>>$ Insert Figure 2.<<}

\section{Xincheng county}

Archival records from the Accounts and Atlas of Jiangxi Province Xincheng County Corvee Census, ${ }^{7}$ preserved in Fudan University, Shanghai, were obtained for Xincheng county in Jiangxi province. This material includes a survey conducted for community security purposes and covering every household in Jiangxi during the Wanli reign (1573-1620) (Guo, 2012). The magistrate Zhao Ricong recorded the details of how household security (Bao Jia Fa) was implemented in the community. To maintain safety, one chief for every 10 households (called Jia, 甲) was in charge of organizing the guard, patrol, and the militia in the case of an attack by bandits. If a bandit attack occurred, every household in the county that had more than one adult male was required to send one member to the militia. This community security system originated from the Song dynasty and was brought into practice in Jiangxi province by Wang Yangming during the Ming dynasty.

The survey for 1681 includes a unique document for Xincheng county, including a list of the occupations of its residents. Although not comparable in scale and scope to modern surveys, it still provides a wider and more accurate distribution than most other data from the pre-1890 period, covering both male and female occupations such as officials, farmers, businessmen, boatmen, monks, nuns, and the unemployed, as well as the less honourable positions of beggar, thief, and prostitute.

As it was based on each household unit, the focus of this survey was largely on adult male taxpayers; hence, we omit nuns and prostitutes as they do not refer to households and their share is thus likely to be underestimated. We define the occupational structure as follows: ${ }^{8}$

\footnotetext{
they became more a social class than an occupational descriptor.

${ }^{7}$ Jiang Xi Xin Cheng Xian bao jia tu ce.

8 Peasants 农民; boatmen 驾船人; labourers 无业佣工; merchants 贸易人; hoteliers 歇店; official 衿监;
} 
Total male adult labour force in agriculture: peasants

Total male adult labour force in industry: labourers

Total male adult labour force in services: merchants + hoteliers + officials + lodgers + monks + Taoists + boatmen $^{9}$

Based on this definition, we can calculate the occupational shares in the total male labour force for Xincheng county to be 67 per cent in agriculture, 2 per cent in industry, and 31 per cent in services (Table 4). Obviously, these shares varied considerably, even within such a small county. Because our data are at the household level, we can plot them per district (i.e., 'Du', a political administrative category under the county level) in Figure 3. In most cases, the proportion of the agricultural population ranges between 50 per cent and 80 per cent, with an average for the county of 67 per cent; the share exceeds 80 per cent in only five districts (grey areas) and drops below 50 per cent in only one district (hashed area).

\section{$>>$ Insert Figure 3.<}

Obviously, this county is unlikely to be representative of China as a whole in 1661, even though, as argued in Section 5, it may represent the faster developing counties that make up about one-third of all counties reported in Table 2. Hence, rather than trying to obtain a picture for the whole of China, we examine how the occupational structure changes over time in this county. To assess this, we compare Xincheng county with analogous information from later periods.

Around a hundred years later, during the Qianlong reign (1735-95), Xincheng's male industrial workers accounted for $\sim 10$ per cent of the population. ${ }^{10}$ This suggests a rapid increase in industrialization from $\sim 2$ per cent in 1661. According to a survey in Republican China in the 1910s, this figure increased even further to $\sim 17.3$ per cent around 1915. The comparison between 1681, 1750, and 1915 is shown in Table 3. Overall, the agricultural share seemed to decline slightly in the Xincheng region while industry increased.

monks 僧人; Taoists 道士; lodgers 寄籍.

${ }^{9}$ As monks and Taoists are not included in the PST system classification, we put these two types into the tertiary sector referring to 'priests' in the PST. In the PST, boatmen belong to the 'Transport and Communications' category, but in ancient China boatmen could be considered to be in the service sector, so we include them in the tertiary sector.

${ }^{10}$ Twenty percent of farmers served in the industrial sector as by-employment (Feng, 1994). 


\section{Ba county (Ba Xian)}

A second unique county sample is available for Ba county, which later became the capital of Chongqing prefecture, located in the east Sichuan basin. Currently, Chongqing is famous for its heavy industry, but the historical archives depict a different picture. ${ }^{11}$ Based on these archives, we are able to calculate the shares of workers in agriculture, industry, and service.

We use the same classification as the PST system to obtain the following definitions: ${ }^{12}$

Agriculture: Owner-peasants + mortgaged peasants + tenant farmers + fishers

Industry: Employers + workers (carpenter) + charcoal burners + craftsmen

Service: Merchants + monks + teachers + doctors + shopkeepers + scholars + Taoists + tailors + cooks + tax-collectors + rice sellers + boatmen.

In this record, the data are organized by sub-county community. A county may be divided into the so-called ' $\mathrm{Li}$ ' and the $\mathrm{Li}$, in turn are subdivided into 'Jia' of a certain number of households. This ' $\mathrm{Li}-\mathrm{Jia}$ ' system ${ }^{13}$ originated from the Ming Dynasty and was an essential sub-county organization for over three centuries.

For Ba county, each $L i$ 's survey is incomplete because the available report covers several subordinate Jia, but not the total $\mathrm{Li}$. In Table 4, the Jia is indicated by a number after the name of the $L i$ to specify which Jia it refers to. For example, the 'Zhi-5' record refers to the Li named Zhi, Jia number ' 5 '.

\section{$>>$ Insert Table $4 .<<$}

The locations of all of the $L i$ can be mapped to the corresponding locations in the gazetteer (see Figure 4). The surveys were conducted beyond the city, south of the Yangtze River. Agriculture accounted for an extremely high proportion, above 75 per

\footnotetext{
${ }^{11}$ These archives were first discovered and transferred to a ruined temple, and were not opened to the public until 1953. They amount to 116,000 volumes, most of which consist of official documents from local government.

${ }^{12}$ Owner-peasants 己田, 自耕, 种土, tenant farmers 佃耕, 耕田, 佃田, mortgaged peasants 当田, tenant farmers 佃土, 佃居, 佃口, charcoal burners 烧炭, scholars 读书, 儒学, tax-collectors 粮差, rice sellers 贩 米.

${ }^{13}$ 里-甲.
} 
cent, with the exception of three $L i$ : Jie and Ren in the far west and Zhi in the east. The Jia for which we have data were located at an average altitude of 210 metres above sea level and it is clear that they were overwhelmingly rural.

$$
>\text { Insert Figure 4.<< }
$$

It is possible to further refine these estimates. From a study of the urban area in 1773 (Tang, 2008), it appears that 51 per cent of the population (male and female) were merchants/storekeepers, 14.3 per cent worked in restaurants and services, 23.7 per cent were transporters, and 5.3 per cent worked in handicraft production. Weighing this urban estimate with the earlier mentioned rural estimates from 1824, and given that the urban population ratio is $16.89 \%$ (Wei, 1989; $\mathrm{Li}, 1993$ ), we can arrive at the following total estimate for Ba county ca. 1790-1800:

$16.89 \% * 0 \%+(83.02 \% * 92 \%)=76.5 \%$ agriculture, $16.89 \% * 5.3 \%+(83.02 \% * 4.7 \%)=4.8 \%$ industry, and $16.89 \% * 94.7 \%+(83.02 * 3.3 \%)=18.7 \%$ services.

A comparison of these estimates with those of later years is shown in Table 5. As would be expected, the share of agriculture decreased between 1790 and 1948, whereas

$$
>\text { Insert Table } 5 .<<
$$

that of services increased. These data can also be compared with those of the adjacent counties Fuling and Da, which show comparable numbers at the start of the twentieth century, even though one has to be careful with data from the 1940s because overwhelming numbers of immigrants arrived in this city during the civil war (Zhou, 1989).

\section{Qufu county}

So far, the only general conclusion seems to be a decline in the share of people working in agriculture. Yet, for industry, we find a rise in Xincheng and stagnation in Ba county, while the reverse is true for services. A third case comes from the archive of the direct descendants of Confucius.

The background of this archive is quite remarkable. Confucianism had gradually become the official ideology of Imperial China since ca. 134 BC. Although the original 
thought of 'Confucianism' had been modified to satisfy the demands of the rulers, Confucius was highly praised by the Chinese regimes in later periods. To express their esteem, the rulers posthumously awarded various exalted titles to Confucius, and provided actual rewards to his direct descendants. In the Western Han Dynasty (206 BC-9 AD), the 13th-generation grandson of Confucius received the title of $\mathrm{Hou}$ (Marquis), and was additionally awarded land for income. Since then, the direct descendants of Confucius have been placed among the ranks of hereditary nobles. In 1055 AD, during the Song Dynasty, direct descendants were awarded the title of Gong (Duke), and entitled Yansheng Gong (literally 'Duke of Sage-Derivative'), which was re-affirmed by all subsequent dynasties until 1935. At that time, the government replaced the aristocratic title with a ministerial-level official position, and this was the only hereditary official title in the Republic of China.

Following Confucius' death, his descendants lived around the Temple and Cemetery of Confucius in Qufu county in Shandong province, which was his birthplace. The home of his direct heirs, located next to the Temple, was called the 'Mansion of the Duke of Sage-Derivative' in the Song Dynasty, and referred to as the 'Kong Family Mansion' for short. After several reconstructions and expansions in later dynasties, the Mansion became a group of buildings protected by a wall. It presently covers an area of approximately 16 hectares and contains 152 buildings. Higher in status than a home or a manor of an aristocratic landowner, the Mansion was considered a small, relatively independent entity and was given land, people, and a full set of administrative organizations by the central government (He, 1981a). Essentially, this regime was de facto independent from local government and was unaffected by dynastic change. It should be noted that during the 2500-year development of the regime, only the eldest grandson among the descendants of Confucius could be the master of the Mansion. Thus, the term 'descendants of Confucius' does not refer to all of his descendants.

Accordingly, the Confucius family left behind an extensive archive, mainly in the Mansion. As states at this UNESCO World Heritage Centre, 'the more than 60,000 files and archives of the Ming and Qing dynasties collected in the Mansion not only provide a credible record of all kinds of activities in the Mansion for more than 400 years, but are highly valuable for studying the history of the Ming and Qing period' ${ }^{14}$ Some of the

\footnotetext{
${ }^{14} \mathrm{http}: / /$ whc.unesco.org/en/list/704.
} 
records offer a relatively detailed occupational description of people living on this land for some benchmark years.

When we focus on the total number of adult male farmers living in the Kong feudal area in 1853 , we find that there are 1,865 entries based on historical materials of the Qufu Kong mansion. ${ }^{15}$ Even though the source claims that the total land of the Kong family is referred to, a comparison of the various available benchmarks shows that it is more likely to refer to 16 zhuang of land that the Kong family owned, 12 in Qufu county and 4 in Sishui county. Estimating the total number of farmers on Confucian land in Qufu county is complicated for two reasons. First, the land the family owned in Qufu county consisted of 1 chang in addition to the 12 zhuang. Second, the units zhuang and chang were far from homogenous and could vary widely from county to county. Hence, it is far from certain that the 12 zhuang in Qufu county are three times as large as the 4 zhuang in neighbouring Sishui county.

Fortunately, we know that 1 zhuang in Qufu county was 5.4 qin $^{16}$ and in Sishui county 15.7 qin, i.e., the total amount of land in zhuang in Qufu county was 64.5 qin versus 62.8 qin in Sishui county. One chang is 19.1 qin, so the ratio of Qufu land to the 16 zhuang of land mentioned earlier is $(64.5+19.1) /(64.5+62.8)=0.66$. Assuming that the number of farmers per unit of land is the same everywhere, then the Confucian lands in Qufu county held about 1,224 adult male farmers in 1853. Likewise, there would have been 1,077 farmers in 1760. What, though, do we know about the non-farm occupations? Fortunately, these are directly observed for 1828 and 1879 . We decided to use the 1828 estimate as it is closest to the agricultural estimate (see Table 6).

However, this does not yet tell us about the development of the occupational structure over time. As pointed out above, in 1760 the number of adult male farmers on Confucian lands in Qufu county was roughly 1,077. However, we need to remember that the Confucian feudal area made up only $66 \%$ of the county total. Hence, again assuming that the number of farmers per unit of land was the same everywhere, we estimate the total number of adult male farmers in this county to be roughly 1,650 in 1760 . We can obtain more information from the Qufu County Gazetteer of the Kangxi Reign (1673), which provides a relatively detailed breakdown of the occupational structure in Qufu

\footnotetext{
${ }^{15}$ Qu fu kong fu dang an shi liao xuan bian, Vol. 3, Book 5, (Ji'nan, 1981), p. 16.

${ }^{16}$ Qing, a unit of area equal to 6.6667 hectares.
} 
county in 1590 . It shows that the share of civilian households is roughly $71 \%$ of the total, non-military, households. Yet, as others have suggested, this is a rather high

$$
>>\text { Insert Table } 6 .<<
$$

estimate compared with our estimate of $63 \%$ farmers in ca. 1830 . This might be because these civilian households were not all farmers. Rather, some of these civilians must also have worked as labourers for the Confucius family. Indeed, a study based on the Confucian family archives and interviews with former servants and farmers of the Confucian family,

\section{>>Insert Table 7.<<}

conducted by the Institute of History, CASS, in the 1960s, shows that these people could act for the family in occupations such as pig, sheep, and cattle farmers, musicians, funeral howlers (employed to express the sorrow of the family during a funeral), and duck egg producers (He, 1981b). Because we know that there were roughly 1,650 adult male farmers (i.e., about 825 households out of a total of 1,305 civilian households), the occupants of 480 households must have had a different occupation.

Interestingly, given the margins of error, the shares of farmers, craftsmen, and service workers in 1590 and 1830-50 are roughly comparable (see Table 7). The similarities cease at the start of the twentieth century according to additional information from the Xiangtuzhi regarding Sishui county ${ }^{17}$, which borders Qufu. The occupational structure was $80 \%$ agriculture, $10 \%$ industry, and $10 \%$ services.

\section{Hua-Lou county}

The fourth case for which we have data from both the Qing dynasty and Republican period is Hua-Lou county (which in 1820 was located in present-day Shanghai), based on the work of Li (2010a). Hua-Lou is actually a combination of two counties, namely Huating county and Lou county, which were merged to become Huating county in $1912 .^{18}$ To avoid confusion, we refer to Hua-Lou when referring to the territory of both

\footnotetext{
${ }^{17}$ Anonymous, Si shui xian xiang tu zhi, 1903.

${ }^{18}$ Two years later, Huating Xian was renamed Songjiang county, and in 1958 was transferred to Shanghai 
counties within their pre-1912 boundaries.

The Hua-Lou area was already an economically advanced region and was located on the territory of what became Shanghai in the nineteenth century. ${ }^{19}$ Based on diverse and scattered sources, Li (2010a) estimated the occupational structure in Hua-Lou county in the 1820 s to be $28 \%$ agriculture, $56 \%$ industry, and $16 \%$ services, although it has been argued that he overestimated the industrial sector. For example, the 1937 Japanese intelligence report on the Hua-Lou Nan Man tetsu (South Manchu railway company) reported the share of

\section{> Insert Table 8.<<}

agriculture as 81 per cent. Li offered the possible explanation that immigration from Hua-Lou to nearby Shanghai county triggered a dramatic reverse trend in the Hua-Lou area (Li, 2010b). However, as the police bureau investigation shows, even in the Shanghai urban area (Shanghai Xian) in 1930, with 348,689 industrial workers, 203 engineers, 89,626 labourers, and 49,190 employees, the industrial sector accounted for no more than 29 per cent of the total population of 1,669,575 (Tan, 2014). Given the urban nature of Shanghai in this period, 29 per cent should be considered the upper limit; that is, Hua-Lou in the 1820s should not exceed this ratio. In addition, the Huating Xiangtuzhi for 1906 shows occupational shares of 82 per cent, 11 per cent, and 7 per cent for agriculture, industry and services respectively for Huating county. As its population did not change between 1820 and 1906, and that its population is about 1.5 times that of Lou county, we can assume that Huating county is less industrialized, and it is very unlikely that the industrial share of Hua-Lou as a whole exceeded 30 per cent in the 1820 s. ${ }^{20}$

The main reason for Li's overestimate of the industry share is his use of $\mathrm{Xu}$ Xinwu's 90.04 per cent ratio to calculate the number of textile workers in rural areas. Applying certain assumptions, Li also calculated the number of textile workers in urban areas; however, he also included part-time textile workers, implying that the time

municipal prefecture jurisdiction and became a suburban district.

${ }^{19}$ What might be somewhat confusing is that at that time there was also a county named Shanghai, at the border of the same prefecture.

${ }^{20}$ Song Rulin and Sun Xingyan, Jia qing song jiang fu zhi, Vol. 28; Gu Lian, Hua ting xian xiang tu zhi, $(1880-1910)$. 
allocated to non-textile activities was added to this total. In addition, irrespective of the part-time issue, the estimated number of persons working in textiles in the Yangtze region is extremely high compared with other regions in China. Hence, by assuming that each person works 300 days instead of 165 (thus only using full-time equivalent workers), by taking the textile worker's share for Jiangsu (where Hua-Lou is located) from $\mathrm{Xu} \mathrm{Xinwu}$, and by further following Li's methodology, we arrive at an occupational distribution of 55 per cent agriculture, 28 per cent industry, and 16 per cent services, which indeed suggests some change to agriculture, but still on a modest scale.

\section{ALTERNATIVE SOURCES OF OCCUPATIONAL DATA WITH AN EXAMPLE OF CRIMINAL RECORDS}

So far, the limited and scattered county-level household occupations have indicated the significance of agriculture. Meanwhile, some counties, such as Xincheng, moved towards industry and services, while others moved only to services (Ba county), remained stable (Qufu county), or deindustrialized (Hua-Lou area). This finding, although interesting because it highlights large economic differences among regions, also paints a bleak picture of the possibility of ever reaching some sort general occupational structure for China for the period prior to the twentieth century. There remain some additional research avenues such as the Ming dynasty occupational households and criminal records, albeit with their own inherent problems.

We start with the Ming dynasty 'occupational household' system, which in theory might supply us with information about the occupational distribution. Indeed, it was a requirement in Imperial China (221 BC to AD 1911) for people to offer (free) labour service to the government, and the government often assigned a specific labour service, as a job, to some parts of the population. At the beginning of the Ming Dynasty, this was formalized into an 'occupation household' system that covered the whole population and all occupations. As such, records of the system might be considered a good source of occupational data; however, there are two problems. First, the majority of the Ming ‘occupation households' were classified as 'civilian households' (民户, min hu). Some authors (e.g., Wang, 1991, p. 26) have labelled this category as 'peasant', but it seems likely that in many cases this type of household might include several different 
occupations, thus biasing any occupational distribution obtained from them. Indeed, looking at Qufu county, as mentioned in the previous sections, we find that only 63 per cent of those recorded as civilian households were actually employed in agriculture. The second problem with these data is that the system was designed such that people were fixed in the occupation that was chosen by the government at the start of the dynasty and were forbidden to move to another profession. This was a largely self-perpetuating system, for example, if a man was assigned to serve the government as a craftsman, then his household would be registered as a 'craftsman household' and his descendants had to follow his path even if they were totally unsuited to this job. From soldier to commander, from farmer to businessman, from craftsman to butcher, all occupations were included and hence all were hereditary. However, this system was entirely based on the government's administrative power, and thus gradually lost its initial function. In practice, people could still change their occupations and social status (Ho, 1962), turning the supposedly continuous updates and revisions of the system into a formality. Hence, these data cannot be viewed as accurately indicating changes in the occupational distribution (Liang, 1950). Partly for this reason, researchers of the population history of the Ming have often suggested that while the 'occupation household' records and statistics of the Early Ming were generally trustworthy, the later 'household' figures should be better viewed as 'tax paying' units rather than actual occupations (Gao, 2013, Cao, 2000, Ho, 1959).

The above shows that data (albeit fragmented) can be obtained from the Ming dynasty gazetteers; given the tradition of recording historical data in gazetteers, these types of data can also be traced in Qing gazetteers. A second potential glimpse of the occupational structure can be found in the Jinshi stone tablets from the Ming Dynasty, which were originally engraved as an honour to the Jinshi, i.e., the winners of the Imperial Examination. Some essential information of the Jinshi was recorded on the stone tablets, including their origin and background. In addition to their hometown, their 'occupation household' registration was included as part of their 'origin'. Scholars have identified almost 20 types of occupations from this source (Zhu, Xie, 1980). However, besides the lack of detail outlined in our discussion of the 'occupation household' system, the jinshi were elites in the civil examination system, and as such, their occupational distribution may be biased. Consequently, previous scholars have tended to 
use these stone tablet records more for regional inequality research than for occupational studies.

A second potential source of occupational data, which we discuss more extensively here, concerns criminal cases. For example, Guo Songyi (2000), later expanded by Wang Yuesheng (2000), used 300 adultery cases from Northeast China to arrive at an estimate of roughly one-third each in agriculture, industry, and services for the Qianlong period (1735-96).

Admittedly, an occupational structure based on criminal records is biased. After all, criminal cases, depending on the type of crime, were not only biased towards lower classes, but also to certain types of offences. It goes far beyond the scope of this paper to deal with these biases in detail, but it is possible to make three preliminary observations on ways that future research may utilize this type of data.

First, one way to eliminate this bias might be to search for a criminal offence that is uncorrelated with occupation. The Handbook of Crime Correlates (Lee, 2009) shows that the use of drug-related products is one of the few crimes that qualifies as such. This may allow us to make a rough estimate of the occupational structure for the nineteenth century because the government increasingly tried to crack down on opium use from the eighteenth century onwards.

A second possible way to correct for biases in occupational data obtained from criminal records is the use of regression analysis. Yet, in order to be able to identify the size of the bias by regression method it is required to make one or more assumptions about the structure of the bias. For example, and without arguing this is correct, in a regression of the share of each occupation on dummies of occupation, province and time, one may assume that the bias is random. Since, in such regressions bias in the Yvariable does not bias the estimates, they can be used to predict the unbiased occupational shares. Another type of assumption may be about the direction of the bias (is it upward or downward).

A third way, if we have estimates for 1770 and ca. 1840, with the latter thus matching our revised benchmark by Guo Songyi for 1850, to use the criminal records to project them back in time. We can apply this method to a dataset of criminal cases involving interest rates, offered to us by Chen Zhiwu from his project on the criminal archives and financial history of China. The data used by Chen, Lin, and Peng (2014) are centred around two benchmarks of 1760 and 1840 and contain $~ 10,000$ cases, each case 
containing a borrower and a lender. We know that roughly one-third of these had occupational data, i.e., a total of roughly

>>Insert Table 9.<<

6,000 occupations. These are well distributed across provinces and he results around 1840 are close to those of Guo (as modified in this text) thus lending credence to the estimates.

\section{LONG-TERM DEVELOPMENTS IN THE OCCUPATIONAL STRUCTURE OF CHINA}

As stated in the introduction, this paper is only intended to provide the first step in creating an occupational structure for early modern China. That being said, in Table 10 we present our overview of the occupational structure in Imperial and Republican China.

The data for 1911-52 are identical to those in Table 1. For 1840 and 1770, the estimates presented are from the criminal records in Table 9, which may be considered the most comprehensive source. The benchmark for 1640 can be obtained from the data of Xincheng and Qufu counties, as follows. First, from Table 2 we identify the counties that have roughly the same agricultural share as Qufu county around 1910, which is roughly two-thirds of all counties. Hence, the economically stagnant Qufu has a share of two-thirds with the remaining third attached to the developing Xincheng county. Second, we weight both counties into three indices for agriculture, industry, and service shares running from 1840 back to ca. 1640. Finally, we link these indices to our 1840 benchmark to obtain the overall occupational shares in 1640, which are listed in Table 10.

$>>$ Insert Table 10.<<

Obviously, it is a far stretch to assume that the weighted population trend over 1640-1840 based on the data from just two counties is representative of China as a whole. Nevertheless, the fact that on average we find little change over time lends some credence to this picture. In addition, the two counties appear to represent different developmental paths within China, with Qufu county showing a decline and Xincheng 
county a rise in industry and services. Indeed, as recorded by the county gazetteer of Qufu county, published in 1934, 'people in the county are short of capital, therefore [t]here is not a single private factory', and more importantly, 'farmers, who are the majority in the county, lack commercial knowledge. In addition, the county-town is distant from a railway station, there is no large-scale output of special local products, thus financial sources are in shortage, and the market is in a depression'. During the 1930s, only seven rural villages and one town street were mentioned for their handicraft production, which included straw mats and hats, mung bean flour, mulberry paper, pottery, woodenware, bricks and tiles. ${ }^{21}$

In contrast, the location of Xincheng county at the boundary of Jiangxi and Fujian provinces enabled it to participate in trade. From Japanese intelligence reported in $1918,{ }^{22}$ we learn that food products entered the region mainly via Nancheng, bordering Xincheng county, and that the major agricultural produce of the region was tobacco, while also exporting substantial amounts of sesame, which were also almost certainly used in traditional oil-extraction industries. Therefore, Xincheng county, which was initially focused on agriculture, increasingly shifted to industrial production.

It is important to cross-check the data in Table 10. One way of doing this is by comparing to other (south) east Asian country studies on occupations. As shown in Table 11, the Chinese estimates are similar to those of the Philippines, Indonesia, and British Malaya. Obviously, there remain regional differences with, for example, the less urbanized outer provinces of Indonesia having a higher share of agriculture than industry, much like the differences between regions in China itself, as pointed out earlier.

\section{> Insert Table 11.<<}

Even though there is a remarkable consistency in the (south) east Asian context, comparison with Western Europe yields a different picture, with the ca. 1930 figures for the (south) east Asian countries being comparable to the period before ca. 1500 in Western Europe. By 1800, however, this picture had changed dramatically, with much higher shares of the workforce employed in industry and services in Western Europe

\footnotetext{
${ }^{21}$ Qufu County Gazetteer, Min guo xu xiu qu fu xian zhi, (1934), p. 116.

${ }^{22}$ Tou a dou bun kai, chyu goku shyou betsu zen shyo, vol. 11, (Tokyo, 1918), p. 124.
} 
(Allen, 2009). For example, the occupational structure outlined in Table 10 for China is relatively similar to the occupational structure of England in 1381 (Broadberry et al., 2015; Shaw-Taylor, 2009). By around 1800, the occupational structure in England had changed significantly, with about one-third of workers in each of the three sectors. As pointed out by, for example, Wrigley (2006), the shift from agriculture to industry and services that occurred in Western economies after ca. 1500 is also likely to signal rising per capita growth, if only because labour productivity was higher in industry and services. Hence, according to Wrigley, Western Europe, and especially England, differed from Asia because the former witnessed a rise in per capita agricultural output, allowing an increasing share of the workforce to be employed in industry and services.

$>>$ Insert Table 12.<<

One way of assessing this claim of rising output per worker in agriculture is to use the estimates of Chinese GDP by economic sector for 1681-1933 calculated by Xu et al. (2017). By combining these data with those of occupational structure in Table 10, we can arrive at sectoral estimates of labour productivity in Table 12. The data in Table 12 also show that labour productivity was highest in industry and services, as is commonly the case in all countries_(Wrigley, 2006). Furthermore, in contrast to England (Broadberry, 2015), agricultural labour productivity in China decreased until the twentieth century. Based on the occupational information currently available, this finding suggests that there is little evidence for substantial artisanal activities during the period 1600-1900 as is sometimes claimed in the Great Divergence debate.

\section{CONCLUSION}

This paper represents a first attempt to shed some light on the occupational structure in the period prior to New China. Modern, through fragmentary, surveys are available from the late Qing. Prior to ca. 1890, however, the style of reporting is different from the subsequent period and the available data are limited to several fragmentary sources.

Nevertheless, two main methods may be used to assess the occupational structure for the earlier periods. The first is to use scarce and fragmentary local household surveys. These sources revealed that the occupational structure between the seventeenth 
and the start of the twentieth century remained virtually unaltered in Qufu county, whereas a small shift towards industry occurred in Xincheng, and towards services in Ba county. In addition, the urban records of Hua-Lou county revealed a decline in both industry and services over this time. The second method is to use larger, country-wide, occupational data from sources such as the 'occupation household' records from the Ming dynasty, and criminal records. Although there are clearly problems associated with these sources, we think they are still promising for future research and propose two possible methods for reducing the bias in data obtained from the criminal records.

Bringing everything together into a tentative overview of the period ca. 1640-1952, from the nineteenth century onwards we found a small rise in industry at the expense of agriculture. Overall, the period was characterized by occupational stability. The credibility of these findings are confirmed by comparison with the sectoral GDP estimates of Xu et al. (2017), which show a slow decline in output per worker in agriculture and industry, combined with a minor rise in services.

\section{REFERENCES}

Allen, R.C. 2009. The British Industrial Revolution in global perspective, (Oxford: Oxford University Press).

Bosma, U. 2017. "Data on Demography, Migration, Slavery and Employment for the Netherlands Indies, the Philippines and British Malaya 1800-1950", http://hdl.handle.net/10622/NCJVLW, IISH Dataverse, V1 [UNF:6:jVCsrqHyhxci3XGhQ8Hi9Q==]

Broadberry, S.N., Campbell, B., and Van Leeuwen, B. 2013. "When did Britain Industrialise? The Sectoral Distribution of the Labor Force and Labor Productivity in Britain, 13811851", Explorations in Economic History 50, no. 1. 16-27.

Broadberry, S.N., Campbel, B., Klein, A., Overton, M., and Van Leeuwen, B. 2015. British Economic Growth 1270-1870, (Cambridge: Cambridge University Press).

Cao, SJ, Zhong guo ren kou shi (Demographic History of China), Vol.4: Ming Dynasty. 2000, Shanghai: Fudan University Press.

Chen, ZW., Lin Z and Peng KX. 2014. "Violent Conflicts in Private Lending: A Research Based on Qing Dynasty's Homicide Reports", Jing ji xue ji kan 9.

Feng E.S. 1994. Zhong Guo She Hui Jie Gou De Yan Bian(The transformation of the China's social structure), (He'nan Press). 
Feuerwerker, A. 1983. “Economic trends, 1912-49,” In: John K. Fairbank (ed.), The

Camabridge History of China 12: Republican China, 1912-1949, Part1, (Cambridge,1983). 28-127.

Gao, SX, Guan yu ming chao de ji guan yu hu ji wen ti (A Study on the Origin and Household Registration in the Ming Dynasty). Journal of Beijing Union University (Humanities and Social Sciences), 2013. 11(1): p. 25-35.

Guo SY. 1991. "The situation of the labor force in the Qing dynasty and a rough estimate of the working population", in Festschrift for the 60-year teaching and research jubilee of Professor Yang Xiangkui, (Hebei Educational Press)

Guo SY. 2000. "An examination of Adultery Affairs on the basis of 403 Civil and Criminal Cases of the Qing Period", Li Shi Yan Jiu 3.

Guo YQ. 2012. "Community self-defense system and population census in China during 16 17 centuries with GIS method", Li Shi Di Li 29.

He LX et.al, 1981a, Feng Jian Gui Zu Da Di Zhu De Dian Xing_—Kong Fu Yan Jiu,(China Social Sciences Press).62.

He LX et.al, 1981b, Feng Jian Gui Zu Da Di Zhu De Dian Xing__Kong Fu Yan Jiu,(China Social Sciences Press).283.

He YM. 2005. Er Shi Shi Ji Zhong Guo Xi Bu Zhong Deng Cheng Shi Yu Qu Yu Fa Zhan(The West China Middle Cities And Regional Development In 20th Centuary ), (Chengdu Press).461.

Ho, Ping-ti, Studies on the Population of China, 1368-1953. 1959, Cambridge: Harvard University Press.

Ho, Ping-ti, The Ladder of Success in Imperial China: Aspects of Social Mobility, 1368-1911. 1962, New York: Columbia University Press.

Lee E et al. 2009. Handbook of Crime Correlates, (Academic Press).

Li BZ., 2010a, Economy in the Early Modern China-GDP Studies in Hua Ting-Lou Xian Area, (Zhong Hua Shu Ju).608-611.

Li BZ, 2010b, Economy in the Early Modern China-GDP Studies in Hua Ting-Lou Xian Area, (Zhong Hua Shu Ju).279-281.

Li SP. 1993. Jin dai si chuan ren kou(The Population of Early Modern China), (Chengdu Press). 220

Li, BZ and Van Zanden, J.L. 2012. "Before the Great Divergence? Comparing the Yangzi Delta and the Netherlands at the Beginning of the Nineteenth Century," Journal of Economic History, 72 (4). 956-989.

Liang, FZ, Ming dai huang ce kao (A Study on Yellow Book of Ming Dynasty). Lingnan Journal, 1950. 10(2): p. 145-172. 
Liu, TC. and Yeh, KC. 1965. The Economy of the Chinese Mainland: National Income and Economic Development, 1933-1959. (Princeton Press).

Maddison, A. 1998. Chinese economic Performance in the Long-run, (Paris), Table D5.

Yin MX., and T Q. 2009. Min guo renkou huji zi liao hui bian di yi ce (Population Collection in The period of the Republic of China, Volume one). (National library Press Fuzhou City).

Moll-Murata, C. 2011. "Methodological paper China 1800, Global Collaboratory on the History of Labor Relations 1500-2000". Downloaded from: https://github.com/rlzijdeman/labrel/blob/master/data/China/China 1800 Methodological Paper.pdf

Ou, PS. 1947. National Income of China, (Academia sinica).

Perkins, D. H. 1969. Agricultural Development in China, 1368-1968, (Chicago)

Pomeranz, K. 2000. The Great Divergence: China, Europe and the Making of the Modern World Economy, (Princeton 2000).

Rozman, G.1981. The Modernization of China, (New York).

Saito, O, and Tadayoshi T. 2006. "A note on the use of the primary-secondary-tertiary (PST) system in East Asian contexts, " Paper presented at the XIV International Economic History Congress, Helsinki.

Shaw Taylor, L. 2009. "The occupational structure of England and Wales, ca. 1750-1900," Paper presented at the INCHOS workshop held in Cambridge July 29th-31 ${ }^{\text {st }}$.

Tan YX, Min guo shi qi cheng shi shi ye wen ti ji qi dui ce yan jiu (1912-1949), (Renmin press,2014), p. 135

Tang, WJ. 2008. Shi Liu Dao Shi Ba Shi Ji Zhong Guo Shang Ren Ge Min, (Studies on 16-18 centuries merchants' revolution), (Beijing: She Hui Ke Xue Wen Xian Chu Ban She).170171.

Usami, Y.2006. "Change in the work force in British India, 1881-1921," Paper presented at the XIV International Economic History Congress, Helsinki 2006, Table 5.

Wang X.1998. "The evolution of modern Chinese craft guilds", Li Shi Yan Jiu 4. 57.

Wang, YQ, Ming chao de pei hu dang chai zhi (The System of Assigning Households to Do Service in Ming Dynasty). Journal of Chinese Historical Studies, 1991(1): p. 24-44.

Wang YS,2000. Qing Dai Zhong Qi Hun Yin Xing Wei Fen Xi- Li Zu Yu 1781-1791 Nian De Kao Cha (Chinese Marriage and Family Research in 18th Century: Analysis Based on The Cases from 1781-1791). Li Shi Yan Jiu 6.

Wei YT.1989. Chong qing cheng shi yan jiu, (Chengdu: Sichuan University Press).382.

Wrigley, E.A.2006. "The transition to an advanced organic economy: half a millennium of English agriculture", The Economic History Review 59(3). 435-480. 
Xu, Y. Shi ZH., Van Leeuwen, B., Ni YP., Zhang ZP. and Ye, M. (2017), 'Chinese GDP, 16611933,' Australian Economic History Review 57(3). 368-93.

$\mathrm{Xu}$, Y. Van Leeuwen, B., and Van Zanden, J.L. (forthcoming), 'Urbanization in China, ca. 1001900,' Frontiers in Economics.

Yamane Y. 1989. Min Sei Shi Seki No Kenkyu, (Tokyo: Gen Mon Shu pan Sha). 177-271.

Zhou Y. 1989. Chongqin: an inland city's rose (Chongqing: Yi ge nei lu cheng shi de jue qi),(Chongqing: Chongqing Press).280,332.

Zhu, BJ and Xie PL, Ming qing jin shi ti ming bei lu suo yin (The index of stone tablet record for Jinshi in the Ming and Qing). 1980, Shanghai: Shanghai Ancient Books Publishing House.

\section{Appendix I: Gazetteers (Xiangtuzhi) with year of publication}

Jinzhou Fu (1901), Changtu Fu (Republican China period), Fu Zhou (1908), Gaiping Xian (1907), Hailong Fu (1907), Zhenan Xian (1910), Kangping Xian (1907), Kuandian Xian (1908), Liaoyang Zhou (1908), Liaozhong Xian (1908), Suizhong Xian (1907), Tieling Xian (1907), Xinmin Fu (1906), Yi Zhou (late Qing period), Xiuyan Zhou (1908), Zhangwu Xian (1908), Fu'an Xian (1906), Zhenfan Xian (1907), Zhenyuan Xian (late Qing period), Haiyang Xian (1908), Chuan Xian (Republican China period), Jing Zhou (1926), Xinning Xian (uncertain—late Qing period), Dongping Xian (1910), Fenghua Xian (1908), Hailong Fu (1908), Liaoyuan Zhou (Republican China period), Liuhe Xian (1907), Nongan Xian (1907), Tonghua Xian (1909), Xingjing Fu (1906), Jian Xian (1915), Huating Xian (1936), Gaochun Xian (1913), Dongping Zhou (1907), En Xian (1908), Fan Xian (1908), Gaomi Xian (1909), Huimin Xian (1908), Liaocheng Xian(1908),Ningyang Xian(1907),Pingyin Xian(1907), Pingyuan Xian (late Qing period), Qihe Xian (late Qing period), Xin Xian (1909), Shouguang Xian (Republican China period), Teng Xian (1907), Wei Xian (1907), Xintai Xian (1908), Yucheng Xian(1908), Zhucheng Xian(1907),Gaotang Zhou(1906),Guantao Xian(1908),Ling Xian(1907), Tangyi Xian (uncertain—late Qing period),Changshan Xian (late Qing period), Wenshui Xian (1909), Yangcheng Xian (1935), Chenggu Xian (uncertain-late Qing period), Fuoping Ting (1908), Liuba Ting (late Qing period), Lueyang Xian (uncertain—late Qing period), Ningqiang Zhou (uncertain—late Qing period), Pingli 
Xian (late Qing period), Shangnan Xian (uncertain—late Qing period), Shang Zhou (late Qing period), Xixiang Xian (1908), Yang Xian (uncertain—late Qing period), Chongning Xian (uncertain — late Qing period), Guan Xian (1907), Jiangbei Ting (late Qing period), Jiangjin Xian (late Qing period), Jintang Xian (1905), Pujiang Xian (uncertain—late Qing period), Tongliang Xian (Republican China period), Wenjiang Xian(1909), Xinfan Xian (1907), Xinjin Xian (1909), Fuyuan Xian (Republican China period), Kuchezhou Benzhou (Republican China period), Wensufu Benfu (1907), Xinping Xian (Republican China period), Luoping Zhou (1907), Tengyue Ting (Republican China period), Changshan Xian (late Qing period), Huolu Xian (1908), Ninghe Xian (late Qing period), Xiong Xian (1905), Yanqing Zhou (1907), Zanhuang Xian (late Qing period), Zhao Zhou (Republican China period), Yongnian Xian (late Qing period)

\section{Appendix II: Regression analysis of data from the criminal records}

In this appendix, we present the two regressions used in Section 4 to reduce bias in the occupational data obtained from the criminal records. Both are weighted by the number of observations. Note that even if individual coefficients are insignificant, this does not apply to the joint significance.

$>>$ Insert Table B1.<< 
Table 1. Labour by economic sector and labour force participation rate, 1850-1933

\begin{tabular}{ccccc}
\hline year & agriculture & industry & services & participation rate \\
\hline 1850 & 83.0 & 8.0 & 9.0 & 42.5 \\
1911 & 76.0 & 9.0 & 15.0 & 47.0 \\
1933 & 80.0 & 7.0 & 13.0 & 51.9 \\
1952 & 77.1 & 7.1 & 14.3 & $36.4 *$ \\
\hline \multicolumn{5}{c}{ *Based on Maddison (1998, Table 3.6). } \\
1911 based on Table 2; 1850; 1850 a reworked version of Guo (1991).
\end{tabular}

Table 2. Employment structure and labour force participation percentage ca. 1911

\begin{tabular}{|c|c|c|c|c|c|}
\hline Province & $\begin{array}{c}\text { Number of } \\
\text { counties with data }\end{array}$ & Agriculture & Industry & Services & Participation rate \\
\hline Fengtian & 23 & 82 & 6 & 13 & 43 \\
\hline Gansu & 2 & 69 & 22 & 9 & 48 \\
\hline Fujian & 1 & 64 & 16 & 20 & 58 \\
\hline Guangdong & 1 & 54 & 28 & 19 & 51 \\
\hline He'nan & 1 & 96 & 1 & 2 & 22 \\
\hline Hu'nan & 2 & 75 & 11 & 13 & 45 \\
\hline Jiangxi & 77 & 59 & 25 & 16 & 55 \\
\hline Jilin & 9 & 90 & 5 & 5 & 43 \\
\hline Jiangsu & 33 & 62 & 8 & 30 & 36 \\
\hline Shandong & 22 & 91 & 2 & 7 & 47 \\
\hline Shanxi & 97 & 68 & 6 & 26 & 53 \\
\hline Shaanxi & 10 & 80 & 4 & 15 & 42 \\
\hline Sichuan & 10 & 68 & 16 & 16 & 51 \\
\hline Xinjiang & 29 & 98 & 1 & 1 & 79 \\
\hline Yunnan & 3 & 76 & 5 & 19 & 55 \\
\hline Zhejiang & 41 & 70 & 11 & 19 & 63 \\
\hline Zhili & 123 & 83 & 5 & 12 & 73 \\
\hline Total* & 481 & 76 & 9 & 15 & 52 \\
\hline
\end{tabular}

Source: Mengxia and Qi (2009, Vols 1 and 3) for Shanxi, Jilin, Jiangsu, Zhejiang, Zhili, Xinjiang, and Jiangxi. All other data are from Xiangtuzhi in the late Qing and early Republican period ca.1890-1910, obtained from http://mylib.nlc.gov.cn/web/guest/shuzifangzhi; Master thesis by Fu Yongxian, Qing mo min chu ren kou shi zheng yan jiu; see Appendix I for all gazetteers.

*Average of provincial means, excluding provinces with only one county. 
Table 3. Male occupational change in Xincheng county region, 1681-1938

\begin{tabular}{lccc}
\hline & agriculture & industry & services \\
\hline 1681 & $67 \%$ & $2 \%$ & $31 \%$ \\
Ca. 1750 & & $10 \%$ & \\
Ca. $1915 *$ & $55.3 \%$ & $17.3 \%$ & $27.4 \%$ \\
\hline \multicolumn{4}{c}{ Source: Mengxia and Qi (2009, volume 2). } \\
& *Male and female.
\end{tabular}

Table 4. Baxian male occupational distribution by sector

\begin{tabular}{|c|c|c|c|c|c|c|c|}
\hline & & Agriculture & $\%$ & Industry & $\%$ & Services & $\%$ \\
\hline 1714 & Zhi-5 & 375 & 97.91 & 0 & 0 & 8 & 2.09 \\
\hline 1780 & Lian-10 & 76 & 100 & 0 & 0 & 0 & 0 \\
\hline \multirow[t]{3}{*}{1813} & Jie- 8 & 151 & 88.30 & 10 & 5.85 & 10 & 5.85 \\
\hline & Ren-9 & 124 & 94.66 & 7 & 5.34 & 0 & 0 \\
\hline & Ren-10 & 53 & 89.83 & 1 & 1.69 & 5 & 8.47 \\
\hline 1814 & Xiao-7 & 176 & 98.32 & 0 & 0 & 3 & 1.68 \\
\hline \multirow[t]{9}{*}{1815} & Zhong- & 46 & 97.87 & 0 & 0 & 1 & 2.13 \\
\hline & 10 & & & & & & \\
\hline & Zhi-6 & 71 & 94.67 & 2 & 2.67 & 2 & 2.67 \\
\hline & Ren-9 & 172 & 75.77 & 43 & 18.94 & 12 & 5.29 \\
\hline & Ren-10 & 91 & 92.86 & 7 & 7.14 & 0 & 0 \\
\hline & Zhi-? & 114 & 67.46 & 28 & 16.57 & 27 & 15.98 \\
\hline & $\mathrm{Ci}-6$ & 152 & 95 & 4 & 2.5 & 4 & 2.5 \\
\hline & Zhi-4,5 & 38 & 97.44 & 0 & 0 & 1 & 2.56 \\
\hline & jie 10 & 77 & 100 & 0 & 0 & 0 & 0 \\
\hline \multirow[t]{2}{*}{1815} & zheng 2 & 221 & 100 & 0 & 0 & 0 & 0 \\
\hline & zhi 6 & 77 & 100 & 0 & 0 & 0 & 0 \\
\hline
\end{tabular}

Source: All of the locations in Chinese are written as '1714: 智里 5 甲; 1780: 廉里 10 甲; 1813: 节里 8 甲, 仁里 9 甲, 仁里 10 甲; 1814 : 孝里 7 甲; 1815 : 忠里 10 甲, 智里 6 甲, 仁里 9 甲, 仁里 10 甲, 直里? 甲, 慈里 6 甲, 直里 4, 5 甲’, respectively. The data for 1774 and 1780 are from the Sichuan archive library and Sichuan University History department, Qing dai qian jia dao ba xian dang an xuan bian, Vol. 2 (Chengdu, 1996), pp. 216, 218, while data for the other years are from pp. 320-327. 
Table 5. Occupational structure of Chongqing and the adjacent area from 1900-49

\begin{tabular}{lllll}
\hline & Year & Agriculture & Industry & Service \\
\cline { 2 - 5 } Ba county* & 1790 & $76.5 \%$ & $4.8 \%$ & $18.7 \%$ \\
Ba county & 1948 & $62.86 \%$ & $3.56 \%$ & $33.58 \%$ \\
Fuling county & 1916 & $65.90 \%$ & $9.88 \%$ & $24.22 \%$ \\
& 1941 & $38.96 \%$ & $5.70 \%$ & $55.34 \%$ \\
Da county & 1920 & $78.71 \%$ & $5.29 \%$ & $16.00 \%$ \\
& 1945 & $76.29 \%$ & $7.13 \%$ & $16.58 \%$ \\
\hline
\end{tabular}

Note: *In 1790, most agricultural workers were male, whereas urban occupations included females.

Because the occupational structure in the countryside for females was largely consistent with that for males, and given the relatively smaller share of women in total occupations, we assumed the final number includes males and females.

Source: (He, 2005); Sichuan Ba xian zhi bian zuan wei yuan hui, Ba xian zhi, (Chongqing, 1994), p. 652. 
Table 6. Occupational structure of Kong's feud in Qufu county ca. 1800-50

\begin{tabular}{|c|c|c|c|}
\hline & Occupation & No. adult males & $\%$ \\
\hline Farmer & Farmer & 1,224 & 62.9 \\
\hline \multirow[t]{8}{*}{ Craftsmen } & Tailor & 6 & 0.3 \\
\hline & Painter & 1 & 0.1 \\
\hline & Carpenter & 27 & 1.4 \\
\hline & Plasterer & 14 & 0.7 \\
\hline & mason & 1 & 0.1 \\
\hline & bucket-maker & 1 & 0.1 \\
\hline & blacksmith & 13 & 0.7 \\
\hline & other craftsmen & 4 & 0.2 \\
\hline \multirow[t]{7}{*}{ Services } & coachman & 11 & 0.6 \\
\hline & kitchen manager & 4 & 0.2 \\
\hline & Cook & 19 & 1.0 \\
\hline & attendant & 17 & 0.9 \\
\hline & Retainer & 21 & 1.1 \\
\hline & Sommelier & 17 & 0.9 \\
\hline & other service workers & 566 & 29.1 \\
\hline Total & & 1,946 & 100.0 \\
\hline
\end{tabular}

Table 7. Occupational structure of Qufu county in 1590 and ca. 1840

\begin{tabular}{lrc}
\hline & $1590 \mathrm{~s}$ & $1830 \mathrm{~s}$ \\
\hline Farmers & $57.50 \%$ & $62.90 \%$ \\
Craftsmen & $4.60 \%$ & $3.60 \%$ \\
Water station attendant & $0.50 \%$ & $0.90 \%$ \\
Temple sweeping & $3.60 \%$ & $/$ \\
Cook & $0.10 \%$ & $1.20 \%$ \\
Medical & $0.10 \%$ & $/$ \\
Other & $33.60 \%$ & $31.40 \%$ \\
\hline
\end{tabular}


Table 8. Occupational structure of Hua-Lou county 1816-20

\begin{tabular}{|c|c|c|c|}
\hline & Hua-Lou 1820 & Huating 1906 & Hua-Lou1930s \\
\hline agriculture & $55 \%$ & $82 \%$ & $80 \%$ \\
\hline industry & $28 \%$ & $11 \%$ & $14 \%$ \\
\hline services & $16 \%$ & $7 \%$ & $4 \%$ \\
\hline Total & $100 \%$ & $100 \%$ & $100 \%$ \\
\hline
\end{tabular}

Source: (Li, 2012); for 1816, see Huating xian xiang tu zhi; for the 1930s, see The Nan Manshyu investigation by the Japanese Intelligence Agency. (Manshyu tetsudou kabushiki kaishya shyanghai jimushyo, kouso shyoukou ken nouso jitai chyosa houkoku)

Table 9. Occupational structure (by percentage) in China ca. 1770 and 1840 based on criminal records

\begin{tabular}{rrrr}
\hline & agriculture & industry & services \\
\cline { 2 - 4 } 1770 & 77 & 6 & 17 \\
$1850 *$ & 83 & 8 & 9 \\
\hline
\end{tabular}

* Guo Songyi ${ }^{1}$ 'The situation of the labour force in the Qing dynasty and a rough estimate of the working population', as modified in this text.

Table 10. Overall occupational structure in China ca. 1640-1952

\begin{tabular}{rrrrr}
\hline & Agriculture & Industry & Services & \\
& & & total & \multicolumn{2}{c}{$\begin{array}{l}\text { Merchants } \\
1640 *\end{array}$} & 82 & 5 & 13 & 5 \\
1770 & 77 & 6 & 17 & 5 \\
1850 & 83 & 8 & 9 & 5 \\
1911 & 76 & 9 & 15 & $6 * *$ \\
1933 & 80 & 7 & 13 & 6 \\
1952 & 77 & 7 & 14 & 5 \\
Note: * Based on the trends in Xincheng for 1681 and Qufu county for 1590 (see text). \\
**Based on data from Jilin (Mengxia and Qin (2009, Volume 1).
\end{tabular}

Table 11. Occupational structure in South (east) Asia ca. 1930 


\begin{tabular}{llrrrr}
\hline & & & agriculture & industry & services \\
\hline China & & 1933 & $80 \%$ & $7 \%$ & $13 \%$ \\
British India & Madras & 1921 & $76 \%$ & $10 \%$ & $14 \%$ \\
& Punjab & 1921 & $58 \%$ & $19 \%$ & $23 \%$ \\
Philippines & & 1939 & $68 \%$ & $15 \%$ & $17 \%$ \\
Indonesia & Java and Madura & 1930 & $72 \%$ & $12 \%$ & $15 \%$ \\
& Outer Provinces & 1930 & $84 \%$ & $9 \%$ & $7 \%$
\end{tabular}

British

$\begin{array}{lllll}\text { Malaya } & 1930 & 61 \% & 12 \% & 27 \%\end{array}$

Source: China: Table 12 this paper; British India: Usami (2006); other countries: Bosma (2017)

Table 12. Labour productivity in China, 1681-1933 (1990 GK dollars)

\begin{tabular}{rcrr}
\hline & Agriculture & Industry & Services \\
\cline { 2 - 4 } 1681 & 1,930 & 3,186 & 2,165 \\
1766 & 1,502 & 1,933 & 1,165 \\
1850 & 1,182 & 1,713 & 1,652 \\
1911 & 1,231 & 1,207 & 1,654 \\
1933 & 932 & 1,526 & 2,016 \\
\hline
\end{tabular}

